\title{
Incidence of thyroid cancer in England by ethnic group, 2001-2007
}

\author{
A Finlayson ${ }^{1}$, I Barnes ${ }^{1}$, S Sayeed ${ }^{1}$, B Mclver ${ }^{2}$, V Beral ${ }^{1}$ and R Ali ${ }^{*, 1,3}$ \\ ${ }^{1}$ Cancer Epidemiology Unit, University of Oxford, Richard Doll Building, Roosevelt Drive, Oxford OX3 7LF, UK; ${ }^{2}$ Mayo Clinic, \\ Rochester, Minnesota, USA and ${ }^{3}$ Faculty of Medicine and Health Sciences, United Arab Emirates University, PO Box \\ 17666 Al-Ain, UAE
}

Background: Thyroid cancer incidence is increasing worldwide, but with large variations in incidence that may reflect either diagnostic bias or true ethnic differences. We sought to determine the effect of ethnicity on the incidence of thyroid cancer in England, a multiethnic population with a single health-care system.

Methods: We analysed 11263 thyroid cancer registrations with ethnicity obtained by linkage to the Hospital Episodes Statistics database. Incidence rate ratios (RRs) adjusted for age, sex and income were calculated for the six main non-White ethnic groups in England compared with Whites and to each other.

Results: Thyroid cancer incidence was higher in all ethnic groups, except Indians, compared with Whites: in Pakistanis (RR 1.79, 99\% floating confidence interval (FCl) 1.47-2.19); Bangladeshis (RR 1.99, 99\% FCl 1.46-2.71); Black Africans (RR 1.69, 99\% $\mathrm{FCl}$ 1.34-2.13); Black Caribbeans (RR 1.56, 99\% FCl 1.25-1.93); and Chinese (RR 2.14, 99\% FCl 1.63-2.80).

Conclusion: The risk of thyroid cancer in England varies significantly by ethnicity. The elevated incidence in most ethnic minorities is unlikely to be due to diagnostic bias and warrants further investigation.

The worldwide incidence of thyroid cancer is increasing (Ferlay et al, 2010) with considerable international variation in incidence (Woodruff et al, 2010). Thyroid cancer is an indolent disease often detected by ultrasound of incidentally discovered nodules and this may be due to diagnostic bias rooted in differential access to health care. (Davies and Welch, 2006). However, other studies suggest changes in risk factors such as iodine supplementation, obesity and the frequency of use of medical diagnostic radiation may be partly responsible (Blomberg et al, 2012; Zhao et al, 2012).

Studying incidence in different ethnic groups in a single country can help to understand this variation (and offer insights into aetiology) as similar diagnostic, reporting and registration procedures are used regardless of ethnic group (Parkin and Khlat, 1996). In England, there were 2208 new cases of thyroid cancer in 2010 with incidence rates having increased by more than 150\% since 1975 (Office For National Statistics, 2011). As a multiethnic nation (14\% of England's population were 'non-White' in 2011 (Office For National Statistics, 2012) with a unified healthcare system, England provides an ideal setting in which to do this.
Since 1995, self-assigned ethnicity has also been recorded in the National Health System's Hospital Episodes Statistics (HES) database (using the same classification system as used in the census) and HES records can now be linked to cancer registrations, providing more reliable information on ethnicity (The Health And Social Care Information Centre, 2011) and allowing individual ethnic groups to be analysed separately for the first time (Jack et al, 2006).

In this paper, we compare the incidence of thyroid cancer among the six largest 'non-White' ethnic groups in England with each other and with Whites using self-assigned ethnicity.

\section{MATERIALS AND METHODS}

We obtained data from the National Cancer Intelligence Network for all cancer registrations from 2001 to 2007 in England with the following information: cancer site coded to the International Classifications of Diseases, 10th Revision (ICD-10; World Health

*Correspondence: Dr R Ali; E-mail: raghib.ali@ndm.ox.ac.uk

Received 16 July 2013; revised 18 December 2013; accepted 19 December 2013; published online 21 January 2014

(C) 2014 Cancer Research UK. All rights reserved 0007-0920/14 
Organisation, 1992); morphology coded to the ICD of Oncology, 2nd and 3rd Revisions (ICD-O-2 and ICD-O-3; World Health Organisation, 1990; World Health Organisation, 2000); deprivation assessed from the income domain of the Index of Multiple Deprivation 2007 (IMD 2007; Noble et al, 2008); age at diagnosis of cancer; sex; ethnicity and regional cancer registry. To determine population incidence data, we used mid-year population estimates produced by the Office of National Statistics from 2001 to 2007 stratified by age, sex and ethnicity.

We used ICD-10 code C73 to identify all thyroid cancers and morphology codes to identify follicular and papillary subtypes. NCRS obtained the self-assigned ethnicity for each cancer registration by record linkage to the HES database. We classified ethnicity as White, Indian, Pakistani and Bangladeshi, with the three groups combined to form the category 'South Asian', Black African, Black Caribbean (again both combined to form the category 'Black') and Chinese.

We estimated age-standardised rates of cancer per 100000 person-years for all ethnic groups using direct standardisation to the 1960 Segi world population (Segi, 1960) with age divided into six categories: $(<40,40-49,50-59,60-69,70-79,80+)$. We used Poisson regression to estimate incidence rate ratios (RRs) comparing each ethnic group (and 'South Asians' and 'Blacks') with Whites adjusting for sex, age and deprivation. We performed pre-specified subgroup analyses by sex (male vs female), age $(<50$ $v s \geqslant 50$ years), deprivation (quintile $1 v s$ quintiles $2-4$ of the income domain of the index of IMD 2007) and by tumour type (follicular $v s$ papillary).

We chose the age division so that cancer rates in first $v$ s later generations of South Asians could be examined - the percentage of South Asians born outside the United Kingdom is $97 \%$ for those aged $\geqslant 50$ years, whereas for those aged $<50$ years the majority (58\%) were born in the United Kingdom (Office For National Statistics, 2001). Subgroup analysis by age for Blacks and Chinese was also done for completeness but it does not allow the same discrimination by generation.
When comparing 'South Asians' and 'Blacks' with Whites, we present results as RRs with 99\% confidence intervals (owing to multiple tests performed across subgroups.) When comparing the individual ethnic groups, we use $99 \%$ floating confidence intervals (FCIs), calculated using the method of floating absolute risks, which enable valid comparisons between any two groups, even if neither one is the baseline (Easton et al, 1991; Plummer, 2004).

As ethnicity information was not complete for all registered cancers, we did a sensitivity analysis using multiple imputations of the missing ethnicity values age, sex, income domain of IMD 2007, site of cancer and region.

Analyses were performed using Stata (version 12; StataCorp, College Station, TX, USA) and R statistical software packages (R Foundation for Statistical Computing, Vienna, Austria).

\section{RESULTS}

Table 1 shows socio-demographic information from the 2001 census by ethnic group. All non-White groups are younger than Whites and all except Chinese are also more deprived, with Pakistanis, Bangladeshis and Black Africans being the most deprived. About half of the South Asian and Black Caribbean populations were born in the United Kingdom compared with only about $30 \%$ of Black Africans and Chinese.

Table 2 shows the total number of thyroid cancer registrations with missing ethnicity values for each subtype.

For all thyroid cancers (Figure 1), there was a statistically significantly higher incidence in all ethnic groups (except Indians) compared with Whites, with significant heterogeneity between the groups $(P<0.001)$. Among South Asians, the rates were statistically significantly higher in both British Pakistanis (RR 1.79, 99\% FCI 1.47-2.19) and British Bangladeshis (RR 1.99, 99\% FCI 1.46-2.71), but not in British Indians (RR 1.09, 99\% FCI 0.90 to 1.32), demonstrating heterogeneity between these groups $(P<0.001)$. In Blacks, the incidence of thyroid cancer was also statistically

Table 1. Comparison of demographic characteristics by ethnic group in England in 2001

\begin{tabular}{|c|c|c|c|c|c|c|c|c|c|c|c|c|c|c|}
\hline & \multicolumn{2}{|c|}{ White } & \multicolumn{2}{|c|}{ Indian } & \multicolumn{2}{|c|}{ Pakistani } & \multicolumn{2}{|c|}{ Bangladeshi } & \multicolumn{2}{|c|}{ Black African } & \multicolumn{2}{|c|}{$\begin{array}{c}\text { Black } \\
\text { Caribbean }\end{array}$} & \multicolumn{2}{|c|}{ Chinese } \\
\hline & $\mathbf{N}$ & (\%) & $\mathbf{N}$ & (\%) & $\mathbf{N}$ & (\%) & $\mathbf{N}$ & (\%) & $\mathbf{N}$ & (\%) & $\mathbf{N}$ & (\%) & $\mathbf{N}$ & (\%) \\
\hline \multicolumn{15}{|c|}{ Census data for 2001} \\
\hline Total population & 42747136 & $(100.0)$ & 1028546 & $(100.0)$ & 706539 & $(100.0)$ & 275394 & $(100.0)$ & 475938 & $(100.0)$ & 561246 & $(100.0)$ & 220681 & $(100.0)$ \\
\hline \multicolumn{15}{|l|}{ Sex } \\
\hline Male & 20828644 & $(48.7)$ & 511204 & $(49.7)$ & 358043 & $(50.7)$ & 138972 & $(50.5)$ & 229103 & $(48.1)$ & 259881 & $(46.3)$ & 105913 & $(48.0)$ \\
\hline \multicolumn{15}{|l|}{ Age } \\
\hline$<50$ & 27665393 & 64.7 & 828200 & 80.5 & 625118 & 88.5 & 248841 & 90.4 & 432985 & 91.0 & 426424 & 76.0 & 184675 & 83.7 \\
\hline $50+$ & 15081743 & 35.3 & 200346 & 19.5 & 81421 & 11.5 & 26553 & 9.6 & 42953 & 9.0 & 134822 & 24.0 & 36006 & 16.3 \\
\hline \multicolumn{15}{|l|}{ Deprivation } \\
\hline Low income (quintile 1) & 7305527 & $(17.1)$ & 347098 & $(33.7)$ & 455710 & $(64.5)$ & 198884 & $(72.2)$ & 277858 & $(58.4)$ & 292537 & $(52.1)$ & 49427 & $(22.4)$ \\
\hline $\begin{array}{l}\text { Middle income } \\
\text { (quintiles 2,3 and 4) }\end{array}$ & 26315786 & (61.6) & 563939 & (54.8) & 222038 & $(31.4)$ & 69325 & $(25.2)$ & 177234 & $(37.2)$ & 245103 & $(43.7)$ & 123994 & $(56.2)$ \\
\hline $\begin{array}{l}\text { High income } \\
\text { (quintile 5) }\end{array}$ & 9125823 & (21.3) & 117509 & (11.4) & 28791 & (4.1) & 7185 & (2.6) & 20846 & (4.4) & 23606 & $(4.2)$ & 47260 & $(21.4)$ \\
\hline \multicolumn{15}{|l|}{ Country of birth } \\
\hline United Kingdom & 41911150 & (98.0) & 472545 & $(45.9)$ & 387198 & $(54.8)$ & 127902 & $(46.4)$ & 161050 & $(33.8)$ & 324764 & (57.9) & 62209 & $(28.2)$ \\
\hline Other & 835986 & $(2.0)$ & 556001 & $(54.1)$ & 319341 & $(45.2)$ & 147492 & $(53.6)$ & 314888 & $(66.2)$ & 236482 & $(42.1)$ & 158472 & (71.8) \\
\hline
\end{tabular}


Table 2. Distribution of registered cancers from 2001-2007 in England by ethnic group (percentages in brackets)

\begin{tabular}{|c|c|c|c|c|c|c|c|c|c|c|}
\hline & White & Indian & Pakistani & Bangladeshi & $\begin{array}{c}\text { Black } \\
\text { African }\end{array}$ & $\begin{array}{c}\text { Black } \\
\text { Caribbean }\end{array}$ & Chinese & $\begin{array}{l}\text { All other } \\
\text { ethnicities }\end{array}$ & $\begin{array}{l}\text { No ethnicity } \\
\text { recorded }\end{array}$ & Total \\
\hline All cancers & $7396(65.7)$ & $178(1.6)$ & $170(1.5)$ & $70(0.6)$ & $124(1.1)$ & $142(1.3)$ & $90(0.8)$ & $1216(10.8)$ & $1877(16.7)$ & 11263 \\
\hline Follicular cancer & $1762(70.7)$ & $20(0.8)$ & $39(1.6)$ & $23(0.9)$ & $32(1.3)$ & $43(1.7)$ & $13(0.5)$ & $203(8.2)$ & $357(14.3)$ & 2492 \\
\hline Papillary cancer & 4195 (63.8) & $128(2.0)$ & $115(1.8)$ & $38(0.6)$ & $67(1.0)$ & $73(1.1)$ & $72(1.1)$ & $808(12.3)$ & $1076(16.4)$ & 6572 \\
\hline Other cancer & 1439 (65.4) & $30(1.4)$ & $16(0.7)$ & $9(0.4)$ & $223(1.1)$ & $26(1.2)$ & $5(0.2)$ & $205(9.3)$ & $444(20.2)$ & 2199 \\
\hline
\end{tabular}

significantly higher in both Africans (RR 1.69, 99\% FCI 1.34-2.13) and Caribbeans (RR 1.56, 99\% FCI 1.25-1.93) but with no heterogeneity between these groups $(P=0.5)$. The risk for thyroid cancer was highest in Chinese (RR 2.14, 99\% FCI 1.63-2.80).

The increased risk in the non-White ethnic groups was evident in men and women, in those aged $<50$ and $\geqslant 50$ years and in those who were most deprived (quintile 1), as well as those in quintiles 2-5.

However, as also shown in Figure 1, in South Asians the rate of follicular thyroid cancer was not statistically significantly higher than in British Whites, whereas the RR for papillary thyroid cancer was statistically significantly higher (RR 1.47, 99\% CI 1.25-1.73). This difference is mainly because of the statistically significantly lower incidence of follicular thyroid cancer in Indians (RR 0.55, 99\% FCI 0.31-0.98), whereas the incidence of both follicular and papillary thyroid cancers were statistically significantly higher in both the Pakistanis (follicular: RR 1.95, 99\% FCI 1.29-2.96, papillary: RR 1.85, 99\% FCI 1.46-2.36) and Bangladeshis (follicular: RR 3.15, 99\% FCI 1.84-5.41, papillary: RR 1.63, 99\% FCI 1.07-2.07).

In Blacks, the incidence of both follicular and papillary thyroid cancers was statistically significantly higher than in Whites. However, the incidence rate ratios were statistically significantly higher in follicular (RR 2.09, 99\% CI 1.53-2.86) than in papillary (RR 1.34, 99\% CI 1.07-1.68), with significant heterogeneity between the two $(P=0.003)$.

The opposite pattern was seen in Chinese, with incidence rate ratios being statistically significantly higher for papillary cancer (RR 2.64, 99\% FCI 1.94-3.58) than follicular cancer (RR 1.38, 99\% FCI $0.68-2.83)$, again with significant heterogeneity between the two $(P=0.03)$.

In the sensitivity analysis, which assigned missing values using multiple imputation, results similar to those shown in Figure 1 were obtained as shown in Supplementary Figure 2 (online).

\section{DISCUSSION}

In this study, we compared, for the first time, incidence rates for thyroid cancers in the main 'non-White' ethnic groups in EnglandSouth Asian (Indian, Pakistani and Bangladeshi), Black (African and Caribbean) and Chinese with Whites and with each other. There was considerable variation by ethnic group, even when gender, age and socio-economic factors are taken into account. Overall, the risk of thyroid cancer was significantly higher in all 'non-White' ethnic groups except Indians, with the increased risk also seen in the subgroupings by gender, age, deprivation and histology. There were significant differences in the incidence of thyroid cancer among South Asians with the risk of both follicular and papillary cancer being higher in Pakistanis and Bangladeshis but not in Indians. The higher rate of thyroid cancer in Blacks was driven principally by an increased risk of follicular cancer, whereas in Chinese, the higher rate was due to an increased risk of papillary cancer.
There is only one previous report of thyroid cancer incidence by ethnicity in England (using name analysis), which showed a higher thyroid cancer incidence in South Asians compared with nonSouth Asians, but only in females (Winter et al, 1999). Studies from the United States have shown a lower incidence in African Americans compared with Whites (Ries et al, 2008), in contrast to our findings, but also found the highest incidence in South East Asians and Chinese, consistent with our results (Spitz et al, 1988).

The different patterns of cancer risk seen across each of the different ethnic groups as well as differences by sex, age, deprivation and tumour subtype suggest that our findings are unlikely to be due to systematic over-reporting of thyroid cancer in the ethnic minority groups. Our previous work using the same data set also showed reduced risks of gastrointestinal cancers in the same ethnic groups that further supports the absence of an overreporting bias (Ali et al, 2013). The differences we found are also between populations with equal access to health care (Nazroo et al, 2009) and there is evidence that non-White ethnic groups are less likely to access services such as cancer screening (Szczepura et al, 2008). It is, therefore, very unlikely that increased access (diagnostic bias) could explain the increased incidence in the non-White groups, although of course there may be other confounding factors, and studies with individual-level exposure are needed to address this.

The environmental and genetic factors that lead to thyroid cancer are not fully known, but there are some established risk factors - pre-existing thyroid disease, iodine status and exposure to radiation (Navarro Silvera et al, 2005). Insufficient iodine in the diet is associated with an increase in the risk of follicular thyroid cancer and it is therefore less prevalent in areas where fortification of salt with iodine is the norm. By contrast, a diet high in iodine, such as one rich in sea food, has been associated with an increased risk in papillary thyroid cancer (Delange, 1998). In the United Kingdom, salt iodisation is long standing and there is no evidence of difference in iodine status by ethnic group and this is therefore unlikely to explain the ethnic variation. The reduced incidence of follicular thyroid cancer in Indians and increased risk of papillary thyroid cancer is striking (a similar pattern is also seen for Chinese) and would be consistent with increased iodine levels but there is no evidence of this. However, some groups - Pakistanis, Bangladeshis and Blacks - have an increased risk of both follicular and papillary cancers, and this cannot be explained by their iodine status.

Other risk factors that are more contentious include an association between increased BMI and thyroid cancer, diabetes, female reproductive factors and exposure to endocrine-disrupting agents (Meinhold et al, 2010; Peterson et al, 2012; Zhao et al, 2012). Although there are some differences in these risk factors (for example, obesity) by ethnic group (Sproston and Mindell, 2006), it is unlikely that this could explain the significant differences in risk we have observed.

Our finding of an increased risk in Blacks is in contrast to studies in the United States but this is likely to be mainly due to a reduction in the recording of thyroid cancer cases in African Americans owing to their inferior access to health care 
Age standardised

Rate per 100000

Ethnic group No.cases person-years

Rate ratio $(\mathrm{FCl} / \mathrm{Cl})^{*} \quad$ Rate ratio $(\mathrm{FIC} / \mathrm{Cl})^{*}$

Both sexes, all deprivation, all ages and tumour types

$\begin{array}{cr}\text { White } & 7396 \\ \text { South Asian } & 418 \\ \text { Indian } & 178 \\ \text { Pakistani } & 170 \\ \text { Bangladeshi } & 70 \\ \text { Black } & 266 \\ \text { Black African } & 124 \\ \text { Black Caribbean } & 142 \\ \text { Chinese } & 90\end{array}$

$\begin{array}{ll}2.0 & 1.00(0.96-1.04) \\ 2.7 & 1.40(1.23-1.60) \\ 2.1 & 1.09(0.90-1.32) \\ 3.5 & 1.79(1.47-2.19) \\ 4.4 & 1.99(1.46-2.71) \\ 3.3 & 1.62(1.37-1.91) \\ 3.6 & 1.69(1.34-2.13) \\ 2.8 & 1.56(1.25-1.93) \\ 4.2 & 2.14(1.63-2.80)\end{array}$

Test of heterogenity between South Asian ethnic groups: $\chi_{2}^{2}=28.4 ; P<0.001$; Black ethnic groups: $\chi_{1}^{2}=0.4 ; P=0.5$ By sex

Male

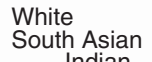

Indian

Black Bangladeshi Black African

Chinese
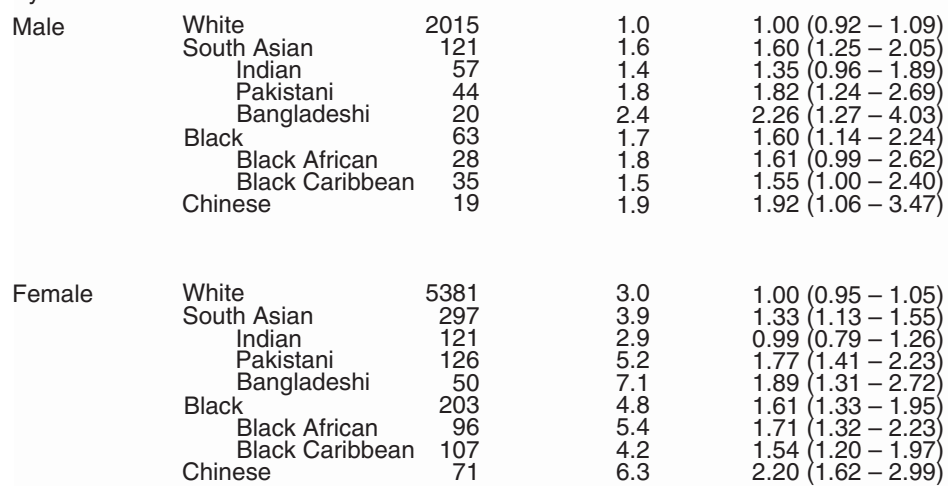

$\begin{array}{rr}5381 & 3 \\ 297 & 3 \\ 121 & 2.9 \\ 126 & 5 \\ 50 & 7 \\ 203 & 4 \\ 96 & 5 \\ 107 & 4 \\ 71 & 6.8\end{array}$

$\begin{array}{ll}3.0 & 1.00(0.95-1.05) \\ 3.9 & 1.33(1.13-1.55) \\ 2.9 & 0.99(0.79-1.26) \\ 5.2 & 1.77(1.41-2.23) \\ 7.1 & 1.89(1.31-2.72) \\ 4.8 & 1.61(1.33-1.95) \\ 5.4 & 1.71(1.32-2.23) \\ 4.2 & 1.54(1.20-1.97) \\ 6.3 & 2.20(1.62-2.99)\end{array}$

Test of heterogenity by sex in: South Asian: $\chi_{1}^{2}=2.6 ; P=0.1$; Black: $\chi_{1}^{2}=0 ; P=1$; Chinese: $\chi_{1}^{2}=0.2 ; P=0.6$

\begin{tabular}{llrll}
\hline By age & & & \\
$<50$ & White & 3297 & 1.6 & $1.00(0.95-1.05$ \\
& South Asian & 280 & 2.1 & $1.34(1.15-1.57$ \\
& Black & 141 & 1.9 & $1.20(0.97-1.50$ \\
& Chinese & 60 & 3.1 & $1.99(1.42-2.77)$ \\
& & & \\
& & & & \\
& White & 4099 & 3.6 & $1.00(0.95-1.05$ \\
& South Asian & 138 & 5.4 & $1.53(1.23-1.90$ \\
& Black & 125 & 8.7 & $2.46(1.95-3.11$ \\
& Chinese & 30 & 8.4 & $2.43(1.52-3.89)$
\end{tabular}

Test of heterogenity by age in: South Asian: $\chi_{1}^{2}=1.4 ; P=0.2$; Black: $\chi_{1}^{2}=31 ; P<0.001$; Chinese: $\chi_{1}^{2}=0.8 ; P=0.4$

By deprivation

Quintile
White
South Asian
Black
Chinese

1136
218
123
23

1.9
3.0
2.8
4.9

$1.00(0.92-1.09)$
3.0
$1.62(1.36-1.93)$

$\begin{array}{ll}.8 & 1.40(1.11-1.77) \\ 4.9 & 2.59(1.51-4.43)\end{array}$

Quintiles 2-5

White

South Asian

Black

Chinese

6260
200
143

143
67

$\begin{array}{ll}2.0 & 1.00(0.96-1.04) \\ 2.5 & 1.25(1.04-1.49) \\ 3.9 & 1.82(1.46-2.25) \\ 4.0 & 1.00(1.46-2.74)\end{array}$

$\begin{array}{ll}2.5 & 1.25 \\ 3.9 & 1.82(1.46-2.25 \\ 4.0 & 2.00(1.46-2.74)\end{array}$

Test of heterogenity by deprivation in: South Asian: $\chi_{1}^{2}=6 ; P=0.01$; Black: $\chi_{1}^{2}=4.1 ; P=0.04$; Chinese: $\chi_{1}^{2}=1 ; P=0.3$

By tumour type

Follicula

White

South Asian

Indian

Black

Bangladeshi

Black African
Black Caribbea

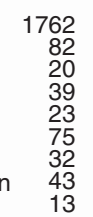

0.5
0.6
0.2
0.8
1.6
0.9
0.8
0.8
0.6

$1.00(0.91-1.09)$
$1.26(0.93-1.69)$
$0.55(0.31-0.98)$
$1.95(1.29-2.96)$
$3.15(1.84-5.41)$
$2.09(1.53-2.86)$
$2.09(1.33-3.30)$
$2.11(1.42-3.12)$
$1.38(0.68-2.83)$

Papillary

White

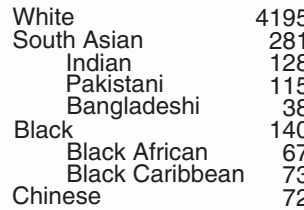

4195
281
128
115
38
140
67
73
72

$\begin{array}{ll}1.3 & 1.00(0.95-1.06) \\ 1.6 & 1.47(1.25-1.73) \\ 1.5 & 1.24(0.99-1.56) \\ 2.3 & 1.85(1.46-2.36) \\ 2.2 & 1.63(1.07-2.48) \\ 1.7 & 1.34(1.07-1.68) \\ 2.0 & 1.37(1.00-1.87) \\ 1.6 & 1.31(0.97-1.77) \\ 3.4 & 2.64(1.94-3.58)\end{array}$

Test of heterogenity by tumour type in: South Asian: $\chi_{1}^{2}=1.4 ; P=0.2$; Black: $\chi_{1}^{2}=8.8 ; P=0.03$; Chinese: $\chi_{1}^{2}=4.6 ; P=0.03$

${ }^{*} 99 \% \mathrm{FCl}$ (squares and lines); $99 \% \mathrm{Cl}$ (diamonds)

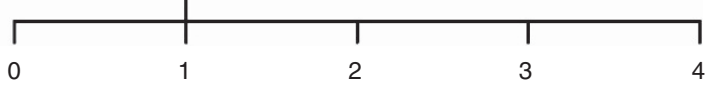

Figure 1. Age-standardised incidence rates and rate ratios (adjusted by age, sex and deprivation) for all thyroid cancer by individual ethnic group compared with Whites. Bangladeshis compared with British Whites. Subgroups show rates and rate ratios subdivided by sex, age, deprivation and by histology (follicular and papillary). 
(Morris et al, 2008) compared with US Whites. It could also reflect differences in the ancestry of the US and UK Black populations, with UK Blacks having migrated relatively recently and coming from the Caribbean and East Africa, whereas US Black immigration is more historic and largely from West Africa (Nazroo et al, 2007).

The increased risk we found in Chinese is consistent with studies in the United States where a higher frequency of thyroid nodules and goitre and reduced consumption of carotenoids explained more than half the increased risk (Haselkorn et al, 2003). Furthermore, the incidence of thyroid cancer in Hong Kong, where the majority of British Chinese originate, is even higher than that in British Chinese (Ferlay et al, 2010). In contrast, rates in the countries of origin for all other ethnic groups in our study is much lower (Ferlay et al, 2010).

The main strength of our study is the use of a reliable and selfassigned measure of ethnicity. We also adjusted for socio-economic status, which is of particular importance for comparisons involving Pakistanis, Bangladeshis and Blacks owing to their higher levels of deprivation. The main limitation of this type of descriptive study is the lack of individual-level information available on exposures. Ethnicity information was also missing for $16.7 \%$ of cancer registrations but the similar results found in the sensitivity analyses suggest that this did not affect our results.

In conclusion, the higher incidence of thyroid cancer in most ethnic minority groups compared with Whites, and the differences by subtype cannot be explained by known risk factors and requires further investigation. Establishing the determinants of this variation with individual-level data of exposures and prevalence of known thyroid cancer genetic risk factors could offer new insights into its aetiology. Our findings also have important public health implications; clinicians serving those areas with large nonWhite populations need to be aware of the increased risk and commissioners need to consider the implications of the increased thyroid cancer incidence for these areas.

\section{ACKNOWLEDGEMENTS}

We thank the National Cancer Registration Service (NCRS) and the Office for National Statistics (ONS) for providing the data.

\section{CONFLICT OF INTEREST}

RA, IB, AF, SS and VB are employed by the Cancer Epidemiology Unit at the University of Oxford, which is supported by Cancer Research UK. BM is employed by the Mayo Clinic in Rochester, MN, USA.

\section{AUTHOR CONTRIBUTIONS}

RA and IB conceived and designed the study. RA, IB, AF and SS contributed to the analysis and interpretation of the data. AF drafted the report, which was critically revised for important intellectual content by RA, IB and SS. All authors approved the report. RA is the guarantor.

\section{DISCLAIMER}

The sponsor of the study had no role in design and conduct of the study; collection, management, analysis and interpretation of the data; and preparation, review or approval of the manuscript.

\section{REFERENCES}

Ali R, Barnes I, Cairns BJ, Finlayson AE, Bhala N, Mallath M, Beral V (2013) Incidence of gastrointestinal cancers by ethnic group in England, 2001-2007. Gut 62(12): 1692-1703.

Blomberg M, Feldt-Rasmussen U, Andersen KK, Kjaer SK (2012) Thyroid cancer in Denmark 1943-2008, before and after iodine supplementation. Int J Cancer 131: 2360-2366.

Davies L, Welch HG (2006) Increasing incidence of thyroid cancer in the United States, 1973-2002. JAMA 295: 2164-2167.

Delange F (1998) Risks and benefits of iodine supplementation. Lancet 351: 923-924.

Easton DF, Peto J, Babiker AG (1991) Floating absolute risk-an alternative to relative risk in survival and case-control analysis avoiding an arbitrary reference group. Stat Med 10: 1025-1035.

Ferlay J, Shin H, Bray F, Forman D, Mathers C, Parkin D (2010) GLOBOCAN 2008 v2.0, Cancer Incidence and Mortality Worldwide: IARC CancerBase No. 10. (Internet). International Agency for Research on Cancer: Lyon, France.

Haselkorn T, Stewart SL, Horn-Ross PL (2003) Why are thyroid cancer rates so high in southeast asian women living in the United States? The bay area thyroid cancer study. Cancer Epidemiol Biomarkers Prev 12: 144-150.

Jack RH, Linklater KM, Hofman D, Fitzpatrick J, Moller H (2006) Ethnicity coding in a regional cancer registry and in Hospital Episode Statistics. BMC Public Health 6: 281.

Meinhold CL, Ron E, Schonfeld SJ, Alexander BH, Freedman DM, Linet MS, Berrington De Gonzalez A (2010) Nonradiation risk factors for thyroid cancer in the US Radiologic Technologists Study. Am J Epidemiol 171: $242-252$.

Morris LG, Sikora AG, Myssiorek D, Delacure MD (2008) The basis of racial differences in the incidence of thyroid cancer. Ann Surg Oncol 15: 1169-1176.

Navarro Silvera SA, Miller AB, Rohan TE (2005) Risk factors for thyroid cancer: a prospective cohort study. Int J Cancer 116: 433-438.

Nazroo J, Jackson J, Karlsen S, Torres M (2007) The Black diaspora and health inequalities in the US and England: does where you go and how you get there make a difference? Sociol Health Illn 29: 811-830.

Nazroo JY, Falaschetti E, Pierce M, Primatesta P (2009) Ethnic inequalities in access to and outcomes of healthcare: analysis of the Health Survey for England. J Epidemiol Community Health 63: 1022-1027.

Noble M, Mclennan D, Wilkinson K, Whitworth A, Barnes H, Dibben C (2008) The English Indices of Deprivation 2007. Communities and Local Government: London, UK.

Office For National Statistics (2001) UK Census.

Office For National Statistics (2011) Cancer Statisitics Registratons, England, UK. Office For National Statistics (2012) Ethnicity and National Identity in England and Wales 2011 (Online) http://www.ons.gov.uk/ons/rel/census/ 2011-census/key-statistics-for-local-authorities-in-england-and-wales/ rpt-ethnicity.htmlAccessed 5 February 2013. Available at http://www.ons.gov.uk/ons/dcp171776_290558.pdf.

Parkin M, Khlat DM (1996) Studies of cancer in migrants: rationale and methodology. Eur J Cancer 32: 761-771.

Peterson E, De P, Nuttall R (2012) BMI, diet and female reproductive factors as risks for thyroid cancer: a systematic review. PLoS One 7 : e29177.

Plummer M (2004) Improved estimates of floating absolute risk. Stat Med 23: 93-104.

Ries LAG, Melbert D, Krapcho M, Stinchcomb DG, Howlader N, Horner MJ, Mariotto A, Miller BA, Feuer EJ, Altekruse SF, Lewis DR, Clegg L, Eisner MP, Reichman M, Edwards BK (2008) SEER Cancer Statistics Review, 1975-2005. National Cancer Institute: Bethesda, MD, USA.

Segi M (1960) Cancer Mortality for Selected Sites in 24 Countries (1950-57). Tohoku University School of Public Health: Sendai.

Spitz MR, Sider JG, Katz RL, Pollack ES, Newell GR (1988) Ethnic patterns of thyroid cancer incidence in the United States, 1973-1981. Int J Cancer 42: 549-553.

Sproston K, Mindell J (2006) Health Survey for England 2004. The health of minority ethnic groups. The Stationery Office: London, UK.

Szczepura A, Price C, Gumber A (2008) Breast and bowel cancer screening uptake patterns over 15 years for UK south Asian ethnic minority 
populations, corrected for differences in socio-demographic characteristics. BMC Public Health 8: 346.

The Health And Social Care Information Centre (2011) How good is HES ethnic coding and where do the problems lie? Online (accessed 8 February 2013).

Winter H, Cheng KK, Cummins C, Maric R, Silcocks P, Varghese C (1999) Cancer incidence in the south Asian population of England (1990-1992). Br J Cancer 79: 645-654.

Woodruff SL, Arowolo OA, Akute OO, Afolabi AO, Nwariaku F (2010) Global variation in the pattern of differentiated thyroid cancer. Am J Surg 200: $462-466$.
World Health Organisation (1990) International Classification for Diseases of Oncology, 2nd Revision. World Health Organisation: Geneva, Switzerland.

World Health Organisation (1992) International Statistical Classification of Diseases and Related Health Outcomes, 10th Revision. World Health Organization: Geneva, Switzerland.

World Health Organisation (2000) International Classification of Diseases for Oncology, 3rd Revision. World Health Organisation: Geneva, Switzerland.

Zhao ZG, Guo XG, Ba CX, Wang W, Yang YY, Wang J, Cao HY (2012) Overweight, obesity and thyroid cancer risk: a meta-analysis of cohort studies. J Int Med Res 40: 2041-2050.

Supplementary Information accompanies this paper on British Journal of Cancer website (http://www.nature.com/bjc) 